\title{
Visual Methods in Ethnographic Fieldwork - on learning from participants through their video-accounts
}

\author{
Ardis Storm-Mathisen (Senior Researcher, Centre for Gender Research (STK), University of \\ Oslo, ardis.storm-mathisen@stk.uio.no)
}

\begin{abstract}
This article reflects on the value of engaging with visual methods in a fieldwork situation. It portrays various forms of visual methods used in a recent research in Botswana and discusses - by using a concrete example - how video-accounts produced by participants and subsequent video-dialogues came to complement insights gained from observation and interviews in fortunate ways. A theoretical value was that the video-recordings - as they represented a 'thicker' description of 'practice in practice' than interview audio recordings or notes from observational situations - helped to build insights into the nonlinguistic, embodied and socio-material aspects of practices. A methodological value was that the use of video-recordings assisted in bringing out participants perspective and thereby helped to produce more relevant data. When participants communicate by recording practices in private spheres this gives an inlet into situations of significance in the everyday that usually are inaccessible for observation and ungraspable through interviews. The video-recordings also had analytical value as they could be used to facilitate a common point of reference for dialogical and collaborative interpretation between the participant and researcher on concrete events. When participants decide what to discuss with the researcher and they together reflect on and put into words what is the meaning of concrete events, this improves the validity of interpretation and fosters a more symmetrical understanding between researcher and participants - hence also of donors and recipients - about what is significant and at stake.
\end{abstract}

Keywords: fieldwork; practice; context; visual; video; method; theory; participant; dialogue

Word count:12754/abstract and title excluded 12464 


\section{Introduction}

A strong strand of critique of mainstream development studies argues that it must move from normative to more contextualized diagnosis of what is good change (i.e. Buch-Hansen and Lauritsen, 2012) and that it is necessary - if we want to understand what development is really about - to study real practices of real people and involve participants in attempts to produce more symmetrical knowledge, rather than have a one-eyed focus on macro-factors (i.e. Chambers 2014; Slater, 2014). This sets new requirements to what are appropriate methodological tools in the field - they must be able to grasp and lift out the nuances of people's concerns and actions. The most common method applied to this end is various types of interview, using language to reveal information that is possible to formulate in a linguistic form. A weakness however is that the data acquired is discursive - it is either about the participant's opinions or perspectives or it is verbal accounts of actions, not the actions themselves. To study the actions themselves many researchers use participant observation, or only observation, to learn from 'being with' and taking in unfolding events through eyes, ears and other senses (i.e. Mead, 1928; Ingold, 2008; Thrift, 2008). Combining observation with participation gives the researcher a wider span of experiences of what it means to be a member of a society and opens up for involving participants as co-researchers and knowing subjects (Chambers, 2014; Bergold and Stefan, 2012). However, what the various forms of participation and observation imply can be diverse and often remains quite vague; hence there is a need to spell out what these various techniques entail. Moreover - since participants and researchers across the globe increasingly engage with media images and visual practices from hand-held devices (Pink 2013) - visual practices are likely to feed into our knowledge constructions in some way or another. It seems therefore also necessary to reflect on how visual methods enter into our research methodologies and how this can affect on our insights. This last appears, not least, highly relevant to development studies, a field calling for more contextualized insights, yet where it is still rather rare to see visual methods actively included and discussed in analyses. ${ }^{1}$ This article takes up this challenge. I will describe various visual methods used in a recent field work in Botswana and discuss - by way of example - how and why video-accounts produced by participants came to complement participant observation and interview methods in valuable ways.

Idioms such as 'A picture is worth a thousand words', suggests there should be an obvious value of using visual methods in fieldwork. Yet, the answers are neither obvious, nor given, as 
to what pictures and moving images can speak that words cannot, how visual methods can become part of ethnographic fieldwork and what the benefits of using visual methods might be. The different visual research traditions - the established sub-disciplines in social anthropology and sociology $\mathrm{y}^{2}$ and the more recent interdisciplinary strands - provide various answers to these questions (see for instance Banks, 2001; Goodwin, 2006; Harper, 2002; Pink, 2013). My approach here is neither realist nor semiotic but inspired by a visual ethnography stance that engages with visual methods as a process of creating and representing knowledge - alongside and complementary to other methods- and as a way to understand our research practice and findings (Pink, 2013: 37). Visual methods are in this sense not fixed procedures, but something that 'should be creatively developed within individual projects' (Pink, 2013:11). I start below by outlining the scope and lens of this particular fieldwork, what various visual methods were developed and why the method of participatory video-voice is my chosen focus here. I then describe - by way of a concrete exemplary case (Flyvbjerg, 2006) - the process whereby this visual method came to produce insight. Finally, I use this case to reflect on how and why the engagement with this visual method complemented insights from participant observation and interviews in theoretically, methodologically and analytically fortunate ways. My primary concern will hence not be with visual methods used for output purposes: how visual data can be used to document, illustrate, communicate and disseminate social science research results, development implementation processes and/or itself be a transformative intervention (but see i.e. Oliveira, 2016; White, 2003). My focus here is rather with the visual as input into the knowledge production itself: how engaging with visual methods can help us approach a more contextualised - situated, symmetrical and processual - understanding of people's concerns and practices (Chambers, 2014; Slater, 2014).

\section{The framework: A study of people's concerns and practices}

I draw on examples from a multi-methodological fieldwork conducted in Botswana from October 2015 to April 2016 in two sites- the capital of Gaborone and a rural village situated at the edge of the Khalahari desert. ${ }^{3}$ The broad scope of this fieldwork was to - by looking at people's everyday concerns and practices - investigate the extent to which, and in what ways,

processes of social change in Botswana were affected by new media. ${ }^{4}$ My discussion here taps into the basic methodological question in this respect - how to go about to learn about people's everyday concerns and practices - and the contribution of visual methods to this end. Three aspects of the theoretical framework that guided the overall project - a non-media 
centric (Morley, 2009) radical practice perspective (Helle-Valle, 2010) inspired by late wittgensteinian thinking - are central to my argument.

Firstly, the theoretical insistence that 'practice must speak for itself' (Wittgenstein, 1979: $\S 139)$. People's practices are fundamental to development, it is something that cannot be determined or explained by models or plans (i.e. DeLanda, 2005; Slater, 2013) and something that only can be grasped through empirical investigation. To study the practices of actual people was therefore core to the fieldwork in question.

Secondly, the methodological implication of this: how to acquire knowledge about people's practices and through which procedures to document and account for it? Wittgenstein underlines with his term 'language game' (i.e.1968: §23) that speaking of language is part of an activity. Hence, practice is more than the use of words and the meanings of words and other performances are always embodied and situated. We therefore need to understand what people's acts are oriented to (what I here will call 'concern', see Goodwin, 2006; Wikan 1992). Methods that can help us make 'thick descriptions' (Geertz 1984) of the situations where acts happen - the embodied, material, relational, representational as well as and nonrepresentational elements and processes (i.e. Burkitt, 1999; Latour, 2005; Thrift, 2008) - and how this links to a wider context (Morley, 2009) are therefore required for a study of practice. The core method to this end is participant observation (i.e. Mead, 1929) and a collaborative and reflexive ethnography where one seeks to learn by 'being with' the people in their settings and environments (Ingold, 2008). Interview methods give in comparison 'thinner' descriptions since it primarily discloses (and allow for documentation) talk about practices, not the enactments of practices themselves (Storm-Mathisen, 2016). The documentation procedures - be they in the form of memory, written notes or various forms of recording - can however be common to both methods. The main methodology applied in the fieldwork was observation and participation: learning by living in the two fieldsites, through getting to know people and by taking part in ongoing social activities. These methods were often combined with other learning and documentation procedures - such as more formal dialogical interviews (of individuals in households, businesses and institutions), digital ethnography, door-to-door-surveys (in households and among individuals), a web-survey, essaycompetitions (at primary and secondary schools), document studies - and various forms of visual methods. I limit my focus below to the visual methods and how they came to 
complement participant observation and interview methods with respect to building 'thick' descriptions of people's practices.

Thirdly, the analytical issue. It follows from the above that all data must be treated as discursive - thus context dependent - and that a study of people's concerns and practices must be approached as individual cases and through various forms of comparison (Flyvbjerg, 2006). Moreover, since 'thick descriptions' requires that analytical generalisations and explanations are linked to people's actual practices, learning from participants is central also in the analysis. How visual methods can be of value in this respect is thence also an issue I will discuss.

\section{How: The use of visual methods in a fieldwork situation}

In visual research (i.e. Banks, 2001; Pink, 2013) a differentiation is often made between methods of visual recording (images produced by researchers to document that which is not easily preserved in fieldnotes), photo/video-voice (where participants are taught to use and given an image making technology to produce images, often self-documentary) and photo/video elicitation (the engagement of participants in interpretations of visual material). ${ }^{5}$ All of the above methods were - in addition to the collection of pre-existing digital and paperbased images - engaged during this fieldwork. ${ }^{6}$ This generated a large body of visual data that, apart from being tremendously varied in content, also differed significantly with respect to type of image captured, who had produced them and for what purpose (see overview below).

\begin{tabular}{|l|l|l|l|}
\hline & $\begin{array}{l}\text { Visual data material } \\
\text { (image type) }\end{array}$ & Produced by (initial purpose) & $\begin{array}{l}\text { Method (image collecting } \\
\text { device) }\end{array}$ \\
\hline 1 & $\begin{array}{l}\text { Visual field notes } \\
\text { (3000 photos and } \\
60 \text { video-clips) }\end{array}$ & $\begin{array}{l}\text { Researchers } \\
\text { during fieldwork/participant } \\
\text { observation } \\
\text { (to capture that which is not } \\
\text { easily preserved in textual } \\
\text { fieldnotes) }\end{array}$ & $\begin{array}{l}\text { (smartphone, tablet and } \\
\text { camera) }\end{array}$ \\
\hline 2 & $\begin{array}{l}\text { Photo survey } \\
\text { (1124 photos taken in } \\
79 \text { percent of the } \\
\text { surveyed households in } \\
\text { the capital and village, } \\
\mathrm{N}=370)\end{array}$ & $\begin{array}{l}\text { Enumerators } \\
\text { during questionnaire-survey } \\
\text { assignment } \\
\text { (to capture images of house } \\
\text { interior-exterior/ domestication } \\
\text { of technologies) }\end{array}$ & $\begin{array}{l}\text { Visual recording } \\
\text { (smartphones) }\end{array}$ \\
\hline
\end{tabular}




\begin{tabular}{|c|c|c|c|}
\hline 3 & $\begin{array}{l}\text { Self-documentary } \\
\text { visual-accounts } \\
\text { (898 video-clips and } \\
\text { more than } 1000 \\
\text { pictures } \mathrm{N}=11)\end{array}$ & $\begin{array}{l}\text { Participants } \\
\text { during their everyday } \\
\text { situations (to capture images of } \\
\text { everyday routines, } \\
\text { surroundings, activities and } \\
\text { concerns as a way to } \\
\text { communicate with researcher) }\end{array}$ & $\begin{array}{l}\text { a) Photo/video voice (tablet) } \\
\text { b) Photo/video elicitation } \\
\text { (tablet) }\end{array}$ \\
\hline 4 & $\begin{array}{l}\text { Collection of pre- } \\
\text { existing images } \\
\text { ( + } 1000 \text { digital images, } \\
100 \text { paper-based } \\
\text { images) }\end{array}$ & $\begin{array}{l}\text { Participants } \\
\text { in private life (to document } \\
\text { personal activities, interests, } \\
\text { and communicate with friends } \\
\text { and family). } \\
\text { Societal institutions } \\
\text { Communication to public (to } \\
\text { inform, promote/ sell) }\end{array}$ & $\begin{array}{l}\text { a) Private captures of events } \\
\text { (smartphones, memory } \\
\text { sticks, social media } \\
\text { accounts) } \\
\text { b) Images produced by } \\
\text { public and private } \\
\text { institutions (laptop, web- } \\
\text { sites, newspapers, pamphlets } \\
\text { etc.) }\end{array}$ \\
\hline
\end{tabular}

Figure 1. Overview of visual methods applied; type of data, producer and methodology.

Although all these visual methods - and the data they generated - to some extent helped to complement insights produced through other (non-visual) methods, the ways they did so varied. Space does not allow me to go into the details; suffice to point out three aspects that affected on how the various visual methods contributed to insights in this particular research. ${ }^{7}$

Firstly, the relative fruitfulness of inputs from visual methods depends on what you want to study and what other inputs you have available and may compare it with. The main aim in this fieldwork was to grasp people's everyday practices and concerns. Although participant observation was the preferred method, this was not possible in all contexts and knowledge of some practices were thus primarily constructed through insights from interviews. It is the value of visual methods in this latter situation that I primarily base my comparison on here.

Secondly, both photo and video recordings capture and preserve a visual representation of the socio-material elements of 'something seen' in one moment so that it can be inspected and restudied at a later moment. Yet there is an obvious difference in what one can learn about practices from studying a frozen image in a photo and through the "visible and hearable actions and interactions of people' (Dant: 2004: 41) in a video-recording. Video-recordings are unique in their capability to preserve more of 'practice in practice' (Pink, 2013: 161) than what is possible to store in memory, note down from observations or grasp by listening to a participant talk. Methods that engaged with video-recordings, more than those that engaged 
with photos, came for this reason to give the most complementary inputs to participant observation and interview methods in this research.

However, and thirdly, visual methods are 'much more than the collection of images as data' (Pink, 2013: 37). Visual images are - like any form of data - representations of reality and cannot be treated as 'transparent', neutral or objective, realist referents of visible and observable phenomena (Banks, 2001). Fruitful inputs from visual methods are therefore often as much about processes to producing and representing knowledge, as it is about the data itself (Pink, 2013: 35). The context of production - the person recording, the camera itself and the situation - will influence on what the camera is 'allowed to see' and record (i.e. Bates, 2013; Pink, 2013). The context of consumption - from where we 'see' the recorded images has in turn an influence on what we see and how we understand it. The participant recorded video-accounts provided in this sense a different potential for insight and had other analytical challenges than my own interview-recordings and video-notes. For instance, when I audiorecorded interviews or took 'video-notes' during participant observation, the object was to capture what participants were doing in that situation. My presence and recording activity had some influence on the situation, on the performance of participants and thus on what was captured in the recording. However, having been present was a resource when I later studied these recordings to gain insights (i.e. investigating micro-processes, critically reflecting on memory or discussing it with others), since it gave me a 'thicker' understanding of what had been going on than what was represented in the recording itself (i.e. Geertz, 1975; Goodwin, 2006; Storm-Mathisen, 1995). The situation was different when participants were making self-documentary 'video-accounts.' This resembled participant observation and interviews in the sense that I had some influence on and indirect presence in these recordings (Bates, 2013) since participants had captured these recordings for the purpose of sharing them with me. A significant difference was however that I was physically absent in the situations where these recordings were made. So, although participant's recordings gave me an opportunity to learn about things I otherwise would have not, I had 'thin' insights into the situatedness of the performances they portrayed. These recordings were thus challenging to treat analytically. The participant produced video-accounts came nevertheless to be the visual method that through the way it engaged participants in the processes of producing and representing knowledge - most radically moved insights beyond that of other methods applied in this research. Hence, the further discussion will focus on this. 
Participant-produced video-accounts and video-elicitation interview

The method of handing over the video camera to participants for them to make recordings what is often referred to as 'participatory video-voice' in the literature (see e.g. Banks, 2001; Bates, 2013; Gibson, 2005; Pink, 2013; Muir and Mason, 2012) - can take various forms. The particular approach in this research - a combination of an initial interview, a video-diary assignment and a successive video-elicitation interview - was inspired by my prior experience with visual approaches, ${ }^{8}$ yet adapted to the purpose of this project and what came to work in the particular environment studied. ${ }^{9}$

Usually the procedure was like this: a selection of the people I had interviewed were asked if they would like to do a 'video-diary'; that is, borrow a project tablet to make short video presentations of themselves, their everyday doings and concerns. The assignment was open, but the participants received an instruction on paper with a suggestion to re-enact some of their every-day activities: i.e. what they usually did in the morning, during daytime, afternoon or evening. Those who wanted to take part were informed about ethical and privacy issues, given some guidance on how to make videos with the tablet, and signed an agreement to borrow the tablet over a period. A date for return of the tablet and a follow-up 'videodialogue' (or video-elicitation interview) was also set up. The video-dialogue had two purposes. Firstly, to reflect with participants on ethical issues of privacy and ownership connected to their production (i.e. what to erase and what could be kept for research, see Pink 2013 and note 5). Secondly, to learn how participants understood, related to and linked the representations in the recordings to their lives and to their participation in the research (see also Oliveira, 2016).

Of the 19-people asked after an interview, ${ }^{10} 11$ women - aged 17-48 from different backgrounds ${ }^{11}$ - ended up producing and agreed to sharing their videos. Their visual production amounted to 98 digital video-clips, covered more than 5 hours and varied in length, genre and content. To give an example of what this method could entail, what the participant's video-clips could be like and how the processes of producing and relating to such clips could generate insights, I now turn to one such case, that of Bontle.

\section{Bontle - the use of video-recordings in the process of producing insights}

The presentation below is organised to mimic the actual process through which insights were produced in the case of Bontle: from how she came to participate in the research, to what she 
said in the first interview, to what was learned when we discussed three video-clips of her choice in the video-dialogue and lastly through a review of all her video-clips at a later stage without her. This process will also suggest to how the visual method complemented inputs from other available methods in her case.

How Bontle became a participant - a female student in higher education Bontle and I had met at various times in the fall of 2015 at the university campus in Gaborone. I did not know much about her, except that she was a student in higher education. This information however was significant.

Botswana, a former British protectorate, has over the last 50 years transformed itself from a predominantly patriarchal peasant society and one of the poorest countries in the world to a middle income country and one of the most educated, gender equal, democratic and mediadeveloped countries on the continent (ITU, 2016; SADC, 2015; UNDP, 2015). Many factors have played into this development but extensive government provision of education has been highlighted as significant (Dryden-Peterson and Mulimbi, 2017). Primary educational enrolment is high in Botswana and gender parity has been achieved to the extent that girls today outperform men in all levels of schooling and outnumber men in tertiary education (SADC, 2015). Yet, the development has many facets. Botswana remains of the world's most unequal countries, with a high level of unemployment and extreme poverty, hence the development plays out differently for different people (World Bank, 2015). Only 20 percent of those between 18 and 24 earn sufficient grades for acceptance to higher education and more than 30 percent of youth in Botswana are unemployed (World Bank 2015).

As a current student in higher education, Bontle was likely to have been provided with full state scholarship (including living expenses) and access to new media curriculum and facilities at the university. She would in this case be positioned not only with higher income, but also with higher access to, competence with and a more complex kind of new media use than many of her country fellows (Storm-Mathisen, 2017). Bontle thus appeared to represent an exemplary case (Flyvbjerg, 2006) of a young woman who had benefited from the 'good developments' in the educational system and a citizen who could contribute to moving Botswana forward in the years to come - as envisioned by her government - 'through effective use of ICT' (Republic of Botswana, 1996). I therefore asked her one day if she would be willing to meet for an interview. 
The initial interview - a clever, ambitious and independent young woman

Bontle agreed to engage in an interview which was conducted early December at the university grounds (she lived some distance away). The interview evolved around her biography, present situation, daily activities, use of new media and future plans. A brief summary (based on the audio-recorded transcript) of what she said is provided below.

Bontle had grown up with her grandmother in a village nearby. Her mother - who was single - had much of the time worked as a maid in the capital. Bontle did not know her father, but had a 10 year younger half-brother. Now she was 21 years old and a fourth year student in social science, one of the youngest in her class. She lived with student friends in a rented house on the outskirts of the city, but went frequently for visits to her aunt who recently had built a house close to the university grounds. Bontle complained it was hard to get by on the student allowance and said 'we do not always have money to eat proper food.' She was looking for a part-time job, but had not found one. Her plan was to complete her BA in 2016. Her hope was to get a job as a cartographer and she said she would be willing to move far away for that if necessary. 'I see myself as an independent lady that can earn for myself', she said. She also dreamed of becoming a writer of romantic novels. Having grown up with very little media Bontle had bought her first mobile phone (a smartphone) and a laptop when she received her first allowance as a university student (she then also got a bank account, an email address and established a Facebook account). Her new devices had however been stolen when 'thieves came into the house early one morning' while she was still asleep and her view now was that 'it's risky to have expensive stuff.' She had at present only a simple mobile phone which could not go on the internet. She liked to watch films and listen to music in her spare-time when there was an opportunity, but her engagement with computer and internet activities was limited to when she was at the lab at the university or at her aunt's place.

Bontle portrays a quite typical Batswana background. Around half of the households in Botswana are female headed - thus often single-income (Statistics Botswana, 2014). Since the work force in Botswana is highly mobile (Hope, 2001), it is quite common for children to stay with relatives (commonly grandmothers) in home villages while their parents pursue work elsewhere. Female headed households, and especially in village settings - where traditional values are claimed to persist the most (e.g. Giddings and Hovorka, 2010) - have been regarded as economic and social vulnerable and the focus of much research and intervention programs. That Bontle, coming from this background, has managed to enrol in higher 
education and has ambitions to become 'an independent woman' suggests to the increased opportunities for social mobility and improved gender mainstreaming over the last generation. Her story represents in this sense a concrete case of the 'good changes' aimed for in national (Republic of Botswana, 1996) and international development initiatives (SADC, 2015). She is likely to be regarded as a representative for 'good change' for other reasons too. The way she tells her story suggests that she has internalized and acted upon education as a central developmental strategy toward becoming independent. This orientation can be linked to a sequential model of trajectory - first education/get an income, then relationships/children much advised by the government (see also Mojula, 2014). Although Bontle is more likely than many others in her age-group to get a job once she completes her BA, unemployment is also high among tertiary graduates and among her peers the combination model education/seek work and having children at the same time - is equally common. ${ }^{12}$ New media on the other hand does not seem very important to how Bontle understands and calculates her future, although she had - like most university students - acquired a smartphone and a laptop for herself when she first moved into the capital (Storm-Mathisen 2017). That she presently only had a simple phone - not a smartphone like most her fellow students - appeared linked to her concern with the risks of with having expensive devices, her strained economic situation and that she had the opportunity to use computers for internet access for free when she needed to.

As what was learned from this interview was primarily word-based, the insights into Bontle's practices and concerns remained rather 'thin'. To engage in participant observation was difficult to arrange in her case, as most of her activities took place too far away from where I worked and stayed. But I asked Bontle at the end of the interview, as an alternative, if she would be interested in borrowing a tablet to make some 'video-accounts' from her everyday. Bontle agreed to do so, was given some instructions on how to use the tablet and signed it out to keep for several weeks (over the Christmas break).

The video-dialogue - Bontle presents her video-accounts

Bontle had made 46 video-clips - covering more than two hours - when she returned with the tablet. This was much more than what would be possible for us to watch through and discuss together. I therefore asked her to select the clips she most wanted to share. She looked over the icons on the tablet, said 'this one I think', and started a clip. I present below a summary of this and the two other clips we watched together, in the chronology whereby she presented them to me and with a few examples of our dialogue around them. ${ }^{13}$ 


\section{The first video-clip - dinner with student friends at home}

It is pitch dark. You can barely see two figures, but there is a lot of talk in Setswana and obviously more people present. The sound is bad; echoing from concrete walls makes it difficult to hear what is said. A voice says: 'this is what we eat when we are broke,' followed by a lot of laughter. The camera moves to show one girl standing, chopping up some tomato and canned meat on a plate, then to Bontle sitting on a chair. The camera turns to the corner of the room where there are 10-15 bottles filled with water on the floor, then to the sink where there are a lot of dirty dishes, and from there - turned sideways - moves out of the kitchen into a hall. The camera-girl knocks on a door and says: 'hello' (to a person inside), 'this is my best friend' (to the camera) 'we are making a documentary' (to the friend behind the door). The door opens, an arm comes out and waves (this friend seems not to want to be video-recorded). The camera starts to move again (like a carousel) and there is again a lot of laughter. Someone says something about 'puking' and 'yard'. The camera follows somebody out to the yard capturing the concrete floor, the sand and a bush outside - then moves back into the kitchen. There is more laughter and the camera turns to Bontle. She is still sitting on the chair, crawling together, hands over her ears. A voice says: 'there you go'. There is again a lot of laughter. Then Bontle's says: 'Oh my God, I shall SO miss you guys'. The camera-girl says: 'Ok. Yes. Another is pregnant. Let's see! Stand up and tighten your... tighten your baby bum'. Bontle stands up, tucks out her belly, touches it and says: 'It's so big'. The camera girl says 'Oh my Gosh it's so big. By nine months you will be so... How much is it?' Bontle replies: 'I'm four months pregnant.' She sits down again. From here the clip goes on with jokes about how to make a baby: 'You know how it's done?' 'Do you use mud?' and so on. They continue to laugh a lot and use high-pitched voices. Gradually the conversation turns to what is healthy to eat and they keep on preparing the food. (Jan 19th 2016, 18 minutes long, clip no 6)

As she started this clip Bontle expressed a concern with the 'poor lighting' in the video and explained that the 'bulbs in the kitchen are bad.' She then began to comment on what was going on:

'we're making dinner. They are teasing me because I like healthy food, but they make unhealthy food. They eat canned meat and cereal, whereas I like sorghum and beans (...) I only make ground food, like I was taught to make at home. They don't like it. 
But I cannot make beans there, it takes too long time to cook and the gas will run out and we share expenses, but morogo I make (sorghum porridge) for breakfast.

Thus, Bontle explains to me the behaviour of herself and the other girls; what they are doing, what they are saying in Setswana and why she was not taking part in making dinner. The first thing this did was to adjust my understanding of what she might have had in mind when she in the initial interview said she could not afford to eat 'proper food.' It was not that they did not have food to eat, but that her friends liked modern food, whereas Bontle preferred to make and eat traditional food because she saw this as more healthy. That she did not make and eat such food now was because they had to cook on gas and this was too expensive (compared to making it on firewood). Bontle's comments to her video-clips thus added to my insights into her practices and the ways she handled her concerns.

When the video-clip reached the part where Bontle was asked to stand up to show she was pregnant, the sound was so bad that I could not hear what was said. I could however see that her friends were talking to Bontle and that she stood up and touched her tummy, so I asked: 'They are talking to you, about your tummy?' Bontle said 'Yeah, I'm pregnant'. This was not something Bontle had said anything about in the first interview and there was no clue to this in how she looked, so the information was new and surprising to me. I asked how long she was along and she said 'Four months. Yeah, Oh!' (Expressing a kind of ambivalence to the situation). Given that single motherhoods are common in Botswana, I wondered about the boyfriend and Bontle said he was older and had a job. I asked 'What will you do when the child is born?' to which Bontle replied 'I am thinking about what to do. I don't know. Should I continue what I do now (school), should I stay at home or should I try to find work?' Bontle communicates with this that she is concerned about how the pregnancy will affect her future. She gives voice to the idea that she has choices, is a bit uncertain, but that one possibility she envisions is to combine education and responsibility for the child (cf. the combination model). To gain more insight into her thoughts around this I asked where she would live after the child was born: 'with the boyfriend?' Her reply to this was firm, signalling she was decided on this:

'No, we'll live separately', 'I don't want to get married, I want to continue my studies, I want to wait. He said he would propose. But, he must know I am too young. Having 
a kid now is ok, but having to deal with the inlaws.... the relatives have started to approach each other'

Her last comment here suggests a marriage process is already considered as having started. Yet, Bontle's stance seems to be to wait and perhaps choose not to marry. Previous research has suggested that Batswana women like Bontle increasingly do not want to marry in the traditional sense (Griffiths, 1997; Helle-Valle, 1997; SADC, 2015; Solway, 2017). This has been explained by several factors, amongst others: migration of men to South African mines in the two previous generations, a weaker institution of marriage, contradictions between the gender equal constitution of the modern common law and the discrimination of women in customary law and that both men and women tend to engage multi amorous relationships. Traditional Setswana wedding arrangements can take very long (years after children are born), families on both sides are very much involved to settle the bogadi (bride price) and after the marriage the woman and children belong to the man and his family (Denbow and Phenyo, 2006). Modern marriages are faster, but more likely to put the couple in financial debt and hence more of a middle class and elite phenomenon (Solway, 2017). In either case, although marriage may give a woman with a child higher status, it can alter her relations, where she can live and often diminishes her individual freedom of choice (Griffiths, 1997). To better understand Bontle's perspective on this I ask about what she can do now, that she cannot do if she marries. She answers 'I can go places, everything'.

This reaffirms that Bontle is concerned with being 'an independent lady' (like she formulated it in the initial interview) and gives more insight into what she means by it. Considering that the above comment is made in a context where her pregnancy is the central frame (brought out by her video-clip), Bontle seems to mean that she can stay independent with a baby, but not if she marries. She wants to keep up her relation to the boyfriend though and says 'we are saving for the baby together, but the child will stay with me. We'll stay in separate houses, and just go for visits.' Hence, Bontle connects independence not merely to the freedom of being able to make decisions for herself, but also to being able to decide for her child. She also expressed an orientation to what this independence could require. She said she planned to send her baby to stay with her grandmother in the village if necessary, but would prefer to stay with her child and hoped to find work in the capital so that she could live with them in the village and just commute back and forth (three hours of travelling every day). An additional insight here is thus that Bontle - when it comes to family life - plans for the future 
in ways that resemble what her mother had done: to have children, but remain unmarried and independent of men. Bontle hoped her boyfriend would keep to her and help with the child even if they did not marry - but she was ready to work and provide for the child herself if not.

\section{The second video-clip - waking up, feeling tired}

The next clip Bontle selected to share was from when she woke up the next day:

The sun is shining. Bontle is in bed, with the camera turned towards her face. She has a groaning voice and explains: 'Oh it's late, what time is it? Can't see but the sun is shining. Now I am looking for that...' She leans over, picks up her mobile from the floor and checks, then says: 'It's seven to 10 and I'm still in bed. I'm sick, constipated, that's why I'm in bed.' (Jan $20^{\text {th }} 2016,2$ minutes long, clip no 7)

When watching this clip Bontle exclaimed 'I was so tired!!! I'm so pregnant, very pregnant', hence pointing out how her new state was affecting her. She then exited this clip, investigated the images of her other clips on the tablet - while saying 'this is...' (reminding herself of their content) - and then started a third clip.

The third video-clip - morning rituals with room-mate, gendered teasing

Bontle's roommate is making a bed in a small room. Bright daylight is coming in from a window (Bontle is holding the camera lying down on the second bed in the room). Bontle says (explaining to the camera): 'She's just made her bed, now she's going to make mine. She's promised to take care of me because I'm pregnant'. The friend replies: 'It's no fun anymore. This is what happens when you're pregnant. Be careful!' They laugh. Bontle says (to her friend): 'you're such a darling, darling in a house'. Bontle moves over to the ready-made bed. Her friend starts making Bontle's bed, but then says (to Bontle): 'I want to change your bedding.' Bontle replies: 'yeah, do what you want', then (to the camera): 'see how she loves me, and then she says I'm abusing her?' The friend replies: 'she IS using me' and ads (in pretend voice):'“I'll tell my boyfriend. Oh, I'm so scared of him. He's so tall, but it doesn't mean he will beat anyone. He's just tall".' The friend complains that she has 'got places to go, people to see', but that she cannot as she has to stay home 'because she [Bontle] is pregnant'. After having made Bontle's bed, the friend carries a bag with clothes over to the bed where Bontle is lying. An old small TV sitting on the top of the dresser can be seen as the camera follows the friend's movements. Bontle gives the camera to her friend, sits 
up, puts the clothes from the bag on the bed and picks up a dress and says: 'Maybe this.' Her friend says: 'it's a dress? A butcher dress? Oh, yeah. Are you gonna cope? Because, you're soo pregnant.' Bontle looks at the dress and says: 'But it kind of makes me feel so big'. The friend says: 'Fat? But you married him fat', but then continues: 'you're not fat'. Bontle is looking at her clothes and exclaims: 'Oh, I'm so indecisive!' She goes to the dresser, picks up her simple phone, shows it to the camera and says: 'my beautiful smartphone' and laughs. The friend turns the camera towards a smartphone charging on the dresser and says 'this is mine'. The friends' phone makes a sound and she checks it. Bontle has now picked up another dress. Her friend says (to Bontle): 'you cannot wear body-hugging', then (to the camera): 'because she's so pregnant' and ads (to Bontle): 'but don't give it away, give it to me'. Bontle picks up yet another dress and says: 'this is what I wore when somebody visited me, and then ran away'. They eventually agree on something Bontle can wear. Bontle gives the camera to her friend and the friend records Bontle as she walks to the kitchen and starts ironing the chosen dress (on top of their small fridge). (Jan 21st 2016, 22 minutes long, clip no 16).

When watching the first part of this third clip Bontle repeated several times 'I am so pregnant', she then laughed and said: 'they are good friends'. To help others is a cultural expectation and value in Botswana (Denbow and Phenyo, 2006) and Bontle here highlights that she has good friends since they offer to help her make her bed and get dressed when she is in a bodily condition and state of energy that makes such tasks difficult. With regards to the incident were her friend talked in pretend voice about the boyfriend ('I'll tell my boyfriend...'), Bontle explained; 'That was an insult. I was seeing someone that was older than me [the present boyfriend]. She is making fun of me. We just like making jokes.' Hence, Bontle points out both what she sees as an insult and that such insults are playful and an accepted form of sociality among her friends. Her comments functioned in this way as important instructions to how the representations on the video should be understood by me.

Bontle had to leave for class after this, so there was no time for us to co-watch the other of her clips. She gave however, before she left, consent for the three clips - and the majority of her other visual production - to be loaded into my computer to keep for further study. 
The video-clips - singularly and as a whole

Bontle and I had only discussed three of the 46 video-clips she handed over. I learned about the content of her other clips when I at a later stage reviewed all her video-clips. This reviewing was quite time-consuming, but also a process where Bontle's video-representations - the form and content of singular clips and as a whole - became a source for insights in itself. This added further to my knowledge about Bontle's practices, concerns and ways of life in various settings, prompted reflections on insights gained from the interview and videodialogue and sometimes opened new questions. A few aspects of this is summed up below.

\section{The video-clips Bontle presented - how it is to be pregnant}

Whereas my primary focus in the video-dialogue had been on how Bontle understood her video-clips, I became more aware of the details in the video-accounts themselves when I later re-viewed them.

The first clip, is recorded by one of Bontle's friends. The friend is presenting the roommates to the activity of making a video-account (i.e. 'we're making a documentary). She is also presenting the four people present (i.e. 'my best friend'), their activities and concerns (i.e. 'this is what we eat when we are broke', 'another one is pregnant') and environment (i.e. the kitchen, the hall, the yard) to the camera. Bontle's friends are obviously having fun with the assignment and laugh and joke about it while also doing other activities. This shows how the camera is not a neutral recording device but takes part in making things happening. Thus similar to a situation of participant observation - some elements of how the girls behave (and what is recorded) are motivated by and performed for the camera (i.e. 'my best friend'), while others are more oriented the other ongoing activities (i.e. preparing food, being together with friends, discussing pregnancy and joking). The video-recording gives clues for insights into these performances. The social interaction between the four girls, their sounds, voices, movements and uses of the material surrounding makes it possible to identify the continuous shifts in the communicative contex (i.e. between frameworks of making the documentary, informing me, instructing eachother and discussing what is healthy to eat). Hence, the recording captures how these girls enact various practices (i.e. of doing a documentary, making food and being together) and how these are oriented to shifting concerns (i.e. little money, healthy/unhealthy food, pregnancy) that are embodied (i.e. Bontle's body posture suggests she is not feeling well, the comment "another one" and the incident of going to the yard and 'puke' suggest there are others present who also are pregnant, yet the laughter and 
high pitch voices of her friends indicate an atmosphere of social gaiety). The video-clip gives through these clues insights into Bontles' practices in a far richer way than her descriptions of these practices in the initial interview. This goes for Bontle's other clips as well, but they portray other situations and it is mainly herself who holds the camera.

Bontle's second clip is from a morning where Bontle has slept late instead of going to the university and gives example of how her pregnancy affects her everyday doings and how she uses her mobile phone in an everyday situation to keep track of time. The third video clip gives insights into how Bontle receives help from her friend in an everyday morning situation (i.e. the friend makes her bed, finds her suitable clothes) and into how they understand Bontle's pregnancy as a change that requires her to act in new ways (i.e. becoming fat, aesthetic concern not to wear body hugging clothes). This clip also gives a glimpse into is how concerns and ideas about more traditional gender roles and power relations are expressed and performed as part of friendship sociality. For instance, Bontle is teasing her friend (by using words that men may say to their women) for playing the roles of good housewives (i.e. 'you're such a darling in a house') and of being subordinate to her (i.e. 'see how she loves me'). Her friend is similarly teasing Bontle for now moving on to a position with less independence (i.e. that she is scared of her boyfriend, sees him as more powerful than herself and is seen as already married to him 'you married him fat') and that she is using her position with the boyfriend (as strong and potentially violent) to threaten them (i.e. 'she IS using me'). Domestic violence is a significant problem in Botswana (SADC 2015) and this video-clip displays how Bontle's friend puts stereotypical cultural representations of Batswana men (i.e. dominant, violent, deceitful) and women (i.e. subordinate, vulnerable, presentable) to use in expressions of concerns for Bontle (i.e. what will become of her now that she is pregnant) and necessary enactments on her part towards this future (i.e. what she can and cannot do as pregnant and soon to be married). Although the third clip displays a bit more new media use than the former two (i.e. the roommate has a more fancy mobile phone than Bontle, and there is a small TV in their room), it's role seem minor in the contexts portrayed.

Bontle's other video-clips - everyday life, family, new media,

Bontle's other video clips demonstrated more the practices she had mentioned in the first interview. She had made several video-tours around her own living quarters, from shopping activities, how she went to her aunt to use a computer, how she logged into Facebook, checked her registration at the university and used the digital library. This, in all, confirmed 
what she had said about her routines in the first interview, yet added much more to it and provided me thus with a more contextualized understanding of these parts of her everyday practices and surroundings. I was first after I had studied these other clips that I came to understand how the three clips she had selected for our dialogue were special in being very explicit accounts of how Bontle's pregnancy affected on her ways of thinking and acting. The first clip introduced Bontle's pregnancy and her concern with having to leave her friends, whereas the second and third clip centered around how her pregnancy affected on her everyday and the way she and others around her thought and acted. That Bontle had selected these clips suggested this was what she wanted to communicate the most and what was a central concern to her. Only one of Bontle's other clips addressed her pregnancy this explicit. This was in the form of a personal diary or confession and felt like a note she had left for me to 'read' in her absence:

Bontle is sitting outside under a tree by herself at lunchtime-camera turned towards her face. She comments that she is having lunch and is waiting to go to the clinic for the check-up. Then she whispers into the camera: 'Oh yeah, because I'm pregnant... and it's bad I can't even sleep, so I really, really need a nurse or a doctor to give me something to help me'. And then.'Oh, did I mention my school. I would like to go to the university and it stopped, Yeah. I'm going to miss school'. (Jan 20th 2016,3 minutes long, her clip no 14).

Bontle seemed here to have concluded her education had to stop, due to the pregnancy. However, since we never got to discuss this clip this interpretation was uncertain and opened up new questions more than giving new insights.

\section{Why: the value of applying visual methods}

The case of Bontle has been presented as exemplary (Flyvbjerg, 2006) to illustrate the process whereby the method of having participants produce video-accounts, engage in videodialogues and the study of their video-clips could generate insights into their concerns and practices. Below I use this case to reflect on why insights from the visual method were of theoretical, methodological and analytical value and a complement to insights about people's practices from participant observation and interviews. 
Theoretical value - improved insights into non-linguistic elements of practice

One methodological challenge connected to the theoretical claim that practice 'must speak for itself' (Wittgenstein, 1979: $§ 139$ ) is how to document practice. Given that practice has meaning that is created with knowledge situated in the body and through activities in a sociomaterial context (Wittgenstein 1979; Burkitt, 1999), practice cannot be represented by what people say alone. Rather, insights into practice require that we grasp what people's acts - their sayings and doings - are oriented to (i.e. Goodwin, 2006; Wikan, 1992). We are assisted in this when we can account for how non-linguistic elements in the context (Geertz, 1975) - i.e. bodies, socialities and materialities - take part in the processes and practices studied (Latour, 2005). Visual tools can be used to capture and document such elements and are hence helpful in this respect. I have focussed on video-recordings - since these have a unique ability to capture and store representations of 'practice in practice' (Pink, 2013) - and given an example of how such recordings helped me attend more to such non-linguistic elements of participant's practices.

If we consider Bontle's video-recordings these are evidently representations. Some of what was represented was talk (i.e. 'this is what we do when we are broke' or 'another one is pregnant'), but a lot was also non-linguistic aspects of doings (i.e. how they made food, that Bontle touched her tummy the way she did, that she used her mobile phone to check the time). Such non-linguistic elements in the video-recordings were central to establish a more nuanced understanding of Bontle's practices (i.e. her media practices were very situated and restricted engagements; not much with friends, more with aunt and for student activities), and not least of what concerns her different practices were oriented to. The way it dawned upon me that pregnancy was a reality and concern for Bontle was not by seeing how her body looked in front of me or hearing what she said, but through how the video represented non-linguistic visual ques about her body posture and bodily performance in another context.

\section{Images can improve our understandings of context-specific performances and embodiment}

The rich opportunity provided by the video-clips for studying non-linguistic ques (i.e. performing pregnancy) - separately and together with the linguistic level of these instances (i.e. 'stand up', 'another one is pregnant') - gave insights into the many rapid shifts in communicative contexts of acts and thus also into how Bontle's knowledge, concerns and practices were situated in her body and in her socio-material surroundings. For instance, although Bontle's pregnancy probably affected her somewhat in all situations (i.e. feeling 
tired), she did not perform it when she was with me in the first interview (i.e. when the framework was her education and ambition to be independent), nor in her video-clips about her new-media practices, whereas it was very much a part of her own and her friends perspectives and performances in her selected video-clips from the private sphere (i.e. when the framework was being tired, receiving help and preparations for the change). That Bontle's pregnancy influenced differently on her perspectives and ways of acting in different situations, gave thus a more nuanced understanding of the embodied, performative and context-specific aspects of her practices.

The video-clip representations helped in such ways to produce 'thicker descriptions' (Geertz, 1975) and insights into Bontle's case compared to what was possible from the interview (and in some ways also compared to what I could have learned had participant observation been possible). Her case is thence also an example of how visual methods can work as aids to improve the theoretical understanding of embodiment, performances and identities (Burkitt, 1999) and socio-material processes (Latour, 2005; Slater 2013). These insights however, are not all about the video-representations themselves, but closely tied to the engagement of participants in the procedure whereby these images were produced and understood. Which is what I address below.

\section{Methodological value - participant engagement gives more relevant data}

To let practice 'speak for itself' (Wittgenstein, 1979 §139) is also connected to another set of methodological challenges, namely how to get access to the settings where the practices we want to study happen and how to engage with people in this setting to learn about their practices in relevant ways. Although 'being with' participants as in participant observation is a core approach to this end (i.e. Ingold, 2008), the power imbalance between researchers and participants can often restrict participants' active engagement and thus our learning from them (i.e. Gibson, 2005). Moreover, physical presence is not always possible for researchers in all settings. Visual methods can be useful tools also in this respect.

\section{Images can provide participants with a way to engage actively in data production}

The case of Bontle illustrate how the method of 'handing the camera' over to participants often worked, in the rather media-restricted environment of Botswana, to motivate participants to engage more actively in the research. It was for instance evident that the 
prospect of having access to a tablet over weeks was an element when Bontle decided to engage in the research beyond the initial interview. ${ }^{14}$ It was also an effective way for me to signal to her that she was 'trusted', given a role beyond being an 'object of study' and that I was interested in her knowledge and needed her active participation to develop an understanding of her reality.

\section{Images can give the researcher an inlet into otherwise inaccessible situations}

The video-recordings produced by Bontle and other participants were often from their private settings and informal everyday activities with friends and family. This gave me an inlet into situations with core centrality in their lives but that would have been very difficult to access through participant observation (e.g. Muir and Mason, 2012). ${ }^{15}$ The difference between hearing Bontle describe her everyday life in the interview (e.g. living with friends and studying) and seeing in her video-clips what her 'places' looked like, how social events with her friends took place and what concerns their acts were oriented to was significant to my insights. My understanding of the everyday practices and concerns of Bontle - and other women - within such private and informal spheres (i.e. with children, family, friends and lovers) would thus have been quite 'thin' where it not for the participant's video-clips from these settings.

\section{Images bring out participants perspectives and concerns}

The tablet and video-recording assignment gave participants a role as co-researcher into their everyday and the video-accounts they produced involved them as knowing subjects in the research (i.e. Chambers, 2014; Bergold and Stefan, 2012). This expanded participants' influence on issues documented, represented and shared in the research (in comparison to when they only took part in an interview or were observed). There was a significant difference in how the interview, video-accounts and the video-interview enabled Bontle to share information about herself and in how I 'was with' Bontle in these situations. The interview is place where the researcher tends to define what and how things are discussed and potential insights are limited to what participants are able to communicate with words. When participants are asked to do video-accounts (even if there is a sort of assignment), it is they who decide what to record and they can through the recording communicate by demonstration not only words. This opens up what participants can 'tell' and establishes a participantdefined frame for what researchers gets to see and what issues are brought into discussions. Bontle clearly acted on this possibility for influence when she produced and presented her 
video-accounts. What she had portrayed in her video-clips was quite varied. However, the clips she chose to share were distant from the new media theme she knew was the topic of the research, and more connected to practices and concerns that mattered most to her at that time. Bontle's video-clips were thus central to bringing her perspective into the dialogue (i.e. it was the clips of her choice that made us talk about her pregnancy). Engaging participant's more actively in research does not level out the power imbalance between researcher and participant (i.e. Gibson, 2005), but it introduces a more open dynamic that can improve insights into what is of relevance to participants. It is however important to be aware that the engagement of participants can also regulate them (Gallagher and Gallagher, 2008) and it is vital that researchers - as the more powerful and responsible partner (i.e. Gibson, 2005) ensure participants feel free to say no and can withdraw when they want.

\section{Images as means for participants to regulate their relationship to the researcher}

The above suggests to some of the ways in which engaging participants in the production of visual material can help to move the knowledge production closer to the perspectives and concerns of participants and thus in a more relevant, open, inductive and symmetrical collaborated direction (Chambers 2014; Slater, 2014). This can also be seen as an effect of a distance inserted by visual images - partly by the time passed from the production of visual accounts to sharing them (participants utterances in an interview is in comparison shared immediately) and partly by breaking the direct eye-to eye contact - between the researcher and the participant that allows for a higher regulation by participants of this relationship. Such distance has value since participants may feel the researcher's attention and direct eyeto-eye contact intimidating (e.g. Oliveira, 2016), not least when the topic shared is of private character. Bontle used the distance afforded by her video-clips to regulate the communication with me. Rather than say she was pregnant, she made it the content of some of her videos and then selected these for us to watch together so that I could ask. Her choice was on the other hand not to select her most confessing and personal video-clip on the issue for co-viewing in the video-dialogue (i.e. the sequence when she reflected on her leaving the university), but to leave it with me to watch when she was not present.

Analytical value - facilitates a common point of reference and shared understanding

Lastly, a vital aspect of letting practice 'speak for itself' (Wittgenstein, 1979 §139) also lies in the analytical; thus, with how researchers interpret and use what is produced through methods 
and represented as data (be it in form of recordings, notes, memory, feelings or other). If one is to take seriously that all meaning is created in context and that knowledge is concretely situated in the body, the analytical implication is that we need to treat data of all kinds as discursive (performative) - hence, as deeds with context-specific meanings (Wittgenstein, 1968; Burkitt, 1999). Another way of saying this is that our analytical interpretations, explanations and generalizations must be linked to what is valid in the context of our data. Vide-accounts can be very helpful in this respect because they provide data of a type that makes it easier to root analytical interpretations (i.e. of linguistic utterances) to a thicker context (i.e. of non-linguistic elements) and because the recorded images can be used to engage with and learn from participants in the actual process of analysis (Pink, 2013).

\section{Images create a common point of reference}

An analytical challenge with verbal accounts in interviews is that they are influenced by the interview but about practices in settings from outside the interview, hence their specific frame of reference is unclear and consequently also the meanings of what participant's say (StormMathisen, 2016). I had for instance taken Bontle's interview statement 'I see myself as an independent woman that can earn for myself', to mean that she regarded education to be a first priority as this would give her a better chance to get formal employment (i.e. sequential model). This meaning was however more a guess than something I could analytically argue as the reference of her statement was unspecific. When images are used as part of interviews this elicits a concrete situation that gives the discussion a clearer context and shared point of reference that can assist researchers in making interpretations closer to participant's perspective (i.e. Bates, 2013; Harper, 2002). I can for this reason convincingly argue that Bontle's talk about independence in the video-dialogue had another meaning; namely to be able to make decisions for herself and her child by not having to depend on a man and his family (i.e. a combination model, independent of men). The enabler for the certainty of this interpretation was that the visual images from her clip gave us a common point of reference and thus a shared context for the questions and answers.

\section{Insights from images with and without participant-dialogue}

The video-dialogues with participants were vital to how thick and solid the insights generated from their video-accounts came to be. Since the video-recordings themselves had not captured all which was relevant for the participant in the context of production (e.g. Bates, 2013; Pink, 2013), I needed help from participants to decode and make proper sense of their recordings. 
The insights produced from the three video-clips Bontle and I discussed were in this respect different from what was learned from those we did not discuss.

One aspect of the challenge was about understanding which elements in the video-clips were staged for the recording event and which were more characteristic of ordinary practices. For instance, I suspected that Bontle's performance of pregnancy in the first video-clip meant she actually was pregnant but could not be sure. That I could ask and have her confirm her pregnancy was a reality, not staged only for the recording, was therefore important. Another aspect of the challenge was that I needed to grasp what the visual representations was about to her, hence how she had experienced the situation portrayed. That Bontle, in the dialogue with me, explained what was going on in the various sequences of the clips and through this instructed my interpretations of these representations - i.e. the insult and how teasing was a way they regulated their various roles to each other as friends and as gender - helped me to learn from her how to understand the video-representations and get a better grasp of the language-games these were parts of (Wittgenstein, 1968). This last part is especially important as data in a sense first becomes valuable at the point when the researcher who is going to use them, understands what they mean. By collaborating on putting into words what was going on and what it meant, my understanding about Bontle's situation - and thus also my analytical claims about it - gained validity.

However, Bontle had also left me with many video-clips that I had to make sense of on my own and where such dialogical interpretations were not possible. For instance, the clip that suggested she had decided to stop her education due to the pregnancy. To better understand such events I had to rely on what I could learn from other methods. For instance, Facebook ethnography suggested Bontle had not graduated, but gone back to stay with her grandmother in the village (i.e. she had stopped her own Facebook postings and her friends wrote about going to her baby-shower). A field visit two years later confirmed this line of events, but also that she had re-enrolled at the university and probably soon would manage to graduate.

This serves to highlight that it was particularly when the participant produced video-accounts allowed researchers and participants to communicate about participant's practices in a concrete way - where frames of reference were brought together to facilitate reflection and dialogue that enhanced understandings (i.e. Bakhtin, in Holquist, 2002) - that they came to produce insights of analytical value. However, what facilitated in all a 'thick' description 
(Geertz, 1973) of Bontle's case, was not the video-clips in themselves, but the process of relational learning and sharing triggered by how Bontle and myself engaged with them and as a driver for and complement to insights from other methods.

\section{Insights into people's concerns and practices - the complementary value of visual methods}

A crucial element in understanding development is to link plans and implementation to the ground, i.e. to what they in fact do to people (Buch-Hansen and Lauritsen, 2012; Chambers, 2014). Efforts to explain these linkages need to uncover and analyse, not only the large, but also the small mechanisms that are in operation. For the latter purpose, investigations must start by looking at people's concerns and practices, hence in individual cases. I have used the case of Bontle as exemplary to illustrate how participatory video-methodology can complement other methods to give insights into such matters. My aim has not been to give a sociological analysis of her case, but rather to use her case to illustrate the process whereby insights into her practices and concerns were built up from the initial interview, through the video-dialogue and her video-accounts in themselves. This has highlighted knowledge construction as a process where insights are gained by comparison and combination of methods and a process where visual methods and participant engagement can enhance insights in theoretical, methodological and analytical fortunate ways. Bontle described herself in the first interview as a young woman who had internalized and acted according to what her government and international agencies envisioned important to 'good development': being ambitious, focused on education, interested in media and striving to become an independent and modern woman.' Her video-accounts demonstrated her practices in these areas, but also how her recent pregnancy affected her ways of acting and thinking in these respects. The video-accounts also facilitated a dialogical and collaborative interpretation - between Bontle and myself - that improved the validity of my interpretations into her situation and fostered a more symmetrical understanding between us. This illustrates how visual methods can be valuable. This is not because images in themselves are worth more than words. It is rather that they can speak of that which lies beyond what we say, is a way to engage participants in the production and construction of knowledge and gives an inlet into what matters to people in developmental processes. Engagements with visual methods can through such processes complement insights from other methods and help us approach a more contextualised understanding of participants worlds. 


\section{References}

Banks, Marcus, 2001, Visual methods in social research. London: Sage

Bates, Charlotte, 2013, 'Video diaries: audio-visual research methods and the elusive body', Visual studies, Vol. 28, No 1, pp. 29-37.

Bergold, Jarg and Thomas, Stefan, 2012, 'Participatory Research Methods: A Methodological Approach in Motion. Forum: Qualitative Social Research, Vol. 13, No. 1. Art. 30.

Buch-Hansen, Mogens and Laurids S. Lauridsen, 2012, 'The Past, Present and Future of Development Studies', Forum for Development Studies, Vol 39, No.3, pp. 293-300.

Burkitt, Ian, 1999, Bodies of Thought. Embodiment, Identity and Modernity. London: Sage. Chambers, Robert, 2014, 'Knowing in Development: A Radical agenda for the twenty-First Century', Forum for development Studies, Vol. 413, No. 3, pp. 525-537.

Dant, Tim, 2004, 'Recording the "Habitus", in C. Pole (ed.), Seeing is Believing? London: Elsevier.

DeLanda, Manuel, 2005, Intensive Science and Virtual Philosophy. London: Bloomsbury Publishing.

Denbow, James and Phenyo C. Thebe, 2006, Culture and Customs of Botswana. Greenwood Press: London.

Dryden-Peterson, Susan and Bethany Mulimbi, 2017, 'Pathways Toward Peace: Negotiating National Unity and Ethnic Diversity through Education in Botswana', Comparative Education Review, Vol. 61. No.1 (February), pp. 58-82.

Flyvbjerg, Bent, 2006, 'Five Misunderstandings about Case-Study Research', Qualitative Inquiry, Vol. 12, pp.219-245.

Geertz, Clifford, 1973, The Interpretation of Cultures. New York: Basic Books.

Gallacher, Lesley Anne, and Gallagher, Michael, 2008, 'Methodological Immaturity in Childhood Research? Thinking through participatory methods', Childhood, Vol. 15, No. 4, pp. 499-516.

Gibson, Barbara E., 2005, 'Co-producing video diaries: The presence of the "absent" researcher', International journal of qualitative methods, Vol. 4, No. 4, pp. 34-43.

Giddings, Carla and Alice Hovorka, J., 2010, 'Place, ideological mobility and youth negotiations of gender identities in urban Botswana', Gender, Place and Culture, Vol. 17, No. 2, pp. 211-229.

Goodwin, Marjorie H., 2006, The hidden life of girls: games of stance, status, and exclusion. Malden, Mass.: Blackwell. 
Griffiths, Anne M. O., 1997, In the shadow of marriage. Gender and justice in an African community. Chicago, University of Chicago Press.

Harper, Douglas, 2002, 'Talking about pictures: a case for photo elicitation', Visual Studies, Vol. 1, No. 17, pp. 13-26.

Helle-Valle, Jo, 1997, Change and diversity in a Kgalagadi village, Botswana. Oslo: Centre for Development and the Environment, University of Oslo.

Helle-Valle, Jo, 2010, 'Language-Games, In/Dividuals and Media Uses: What a Practice Perspective Should Imply for Media Studies', in Birgit Bräuchler and Jack Postill, eds., Theorising Media and Practice, Oxford: Berghahn, pp. 271-301.

Holquist, Michael, 2002, Dialogism: Bakhtin and his world. London: Routledge

Hope, Ron, K., 2001, 'Population Mobility and Multi-Partner Sex in Botswana: Implications for the Spread of HIV/AIDS', African Journal of Reproductive Health, Vol. 5, No. 3, pp. 73-83.

Ingold, Tim, 2008, 'Anthropology is not Ethnography', Proceedings of the British Academy, Volume 154.

Latour, Bruno, 2005, Reassembling the Social. An Introduction to Actor-Network-Theory, Oxford: Oxford University Press.

ITU, 2016, Measuring the information society report 2016. Geneva: International Telecommunications Union.

Mead, Margaret (1928) Coming of age in Samoa: a psychological study of primitive youth for Western civilisation. New York: William Morrow \& Co.

Mojola, Sanyu, A. 2014, Love, money and HIV. Becoming a modern African woman in the age of AIDS, Oakland: University of California Press.

Morley, David, 2009, 'For a Materialist, Non-Media-Centric Media Studies', Television and New Media, Vol 10, pp. 114-116.

Muir, S and Mason, J, 2012, 'Capturing Christmas: the sensory potential of data from participant produced video', Sociological Research Online, Vol 17, No 1.

Oliveira, Elsa, 2016, 'Empowering, invasive or a little bit of both? A reflection on the use of visual and narrative methods in research with migrant sex workers in South Africa', Visual Studies, Vol 31, No 3, pp. 260-278.

Pink, Sarah, 2013, Doing Visual Ethnography (third edition). London: Sage.

Republic of Botswana (1996). National development vision 2016.

SADC, 2015, SADC Gender protocol Barometer 2015 Botswana.

Slater, Don, 2013, New Media, Development and Globalization. Cambridge: Polity Press. 
Solway, Jackeline, 2017, “"Slow marriage”, "fast bogadi": change and continuity in marriage in Botswana', Anthropology Southern Africa, Vol. 39, No. 4, pp. 309-322.

Statistics Botswana, 2014, Botswana household access and individual use of information \& communication technologies - 2014. Stats brief.

Storm-Mathisen, Ardis, 1995, 'Walkers, non-talkers. A sociological study on peer interaction among toddlers in pre-schools'. Hovedoppgave. Institutt for sosiologi. Universitetet $\mathrm{i}$ Oslo.

Storm-Mathisen, Ardis, 2016, 'Grasping children's media practices - theoretical and methodological challenges', Journal of Children and Media 2016, Vol. 10, No. 1, pp. 8189.

Storm-Mathisen, Ardis, forthcoming 2017, 'New media use among young urban Batswana concerns and consequences', in Poul Erik Nielsen, Jessica Gustafsson and Teke Ngomba, eds,. New Media and Processes of Social Change in Contemporary Africa, Århus: Nordicom.

Thrift, Nigel (2008). Non-Representational Theory: Space, Politics, Affect. London: Routhledge.

UNDP, 2015, Briefing note for countries on the 2015 Human Development Report Botswana.

White, S, 2003, Participatory Video: Images that Transform and Empower. London: Sage.

Wikan, Unni (1992). 'Beyond the words: the power of resonance', American Ethnologist, 19 (3): 460-482.

Wittgenstein Ludvig, 1979, On Certainty. Oxford: Basil Blackwell

Wittgenstein, Ludvig, 1968, Philosophical Investigations. Oxford: Basil Blackwell.

World Bank, 2015, Botswana Poverty Assessment. Report No. 88473-BW.

Young, Lorraine and Barrett, Hazel, 2001, 'Adapting visual methods: action research with

Kampala street children', Area, Vol. 33, No. 2, pp. 141-152.

\footnotetext{
${ }^{1}$ A quick search in the Forum for Development Studies journal website in August 2016 did not give one single hit of studies where 'video' or 'picture' or 'visual' data was used as part of the analysis presented. However, uses of visual tools have been argued for elsewhere in the literature on development, especially within action and participatory research strands (see for instance Young and Barrett, 2001).

${ }^{2}$ See for instance Journal of Visual Anthropology, Journal of Visual Sociology, Visual studies and the interdisiplinary journal Visual Studies.

${ }^{3}$ Sites were chosen to compare with fieldwork from the 90's (Helle-Valle, 1997).

${ }^{4}$ The full project name is New Media Practices in a Changing Africa. The project runs from 2015-2018, and is funded by The Research Council of Norway, FRIPRO. See more on project webpage: www.mediafrica.no.

${ }^{5}$ Visual methods require the same kind of ethical considerations as other ethnographic methods. However, images can be very personal and invasive, hence good routines to secure protection of participant's privacy and rights are important. In this fieldwork active written consent to capture their images (and how to use them) was collected from all participants.
} 
${ }^{6}$ The recording equipment used included personal smartphones and two digital cameras plus five tablets belonging to the project.

${ }^{7}$ Common to all these visual methods were the importance of and challenges connected to: i) protecting the privacy and rights of people who were photographed/filmed (as well as ownership rights to the produced images), ii) acquiring sufficient technical knowledge on how to use the visual recording, storing and processing devices (i.e. to ensure good recordings, protect devices from viruses and malware and have sufficient storage space), iii) dealing with the dependency on electricity and possible vulnerability to robbery and iv) finding ways to manage the very time consuming process of looking through, interpreting, analyzing and transforming visual data into words and written text.

${ }^{8}$ I.e. 'classic' video ethnography (Storm-Mathisen, 1995) and versions of the Pink-inspired (2013) 'collaborative video-tour' and 'video-reenactment' (i.e. Storm-Mathisen, 2016).

${ }^{9}$ I.e. the 'video-tour' method (Pink, 2013) was either too intrusive or not practical in this environment since activities often happened outside with many people present and many lived in small houses or far away.

${ }^{10}$ The selection of these informants was pragmatic. Enough trust had to be established between the research participant and myself for me to lend out the tablet. Both men and women were asked, but the men were reluctant to engage with the task. Some of the people asked did not want to borrow the tablet because they felt they could not manage it (unfamiliar with the touch screens), could not charge it (no electricity at home), were concerned about their own security (feeling it exposed them to robbery) or they did not want to take responsibility for a valuable device (compared to most mobile phones this tablet was rather big and difficult to hide from others, and it was rare for people to have tablets, especially in the village). Four participants came back with empty tablets; partly due to not understanding how to use it and partly that they did not want to or had not found time to produce visual material.

${ }^{11}$ In the village: Two female household heads, one high-school student and one unemployed in her 20's. In the capital: a high-school student and her working-class family, four university students and two state employees in their 20s.

${ }^{12}$ Motherhood is a central feature in Batswana femininity (Giddings and Hovorka, 2010). The mean age for first child is 20 years, 92 percent all women age 15-49 have children and very few are married (Statistics Botswana, 2014).

${ }^{13}$ At the time, only Bontle knew what was on the videos, my knowledge was restricted to what she had told me about herself in the first interview. The transcripts presented below were written after several re-viewings of her visual production at a later stage and are made brief to give an impression of what went on in these clips and their central characteristics.

${ }^{14}$ This varied however. People who had devices themselves were less eager and others could be reluctant to take responsibility for an expensive device of fright for theft or robbery.

${ }^{15}$ Unless you are willing to move in with people for a longer period (which we did in this project), but then you can cover very few cases. 